\title{
THE DIGITAL MEDIATION OF MIGRATION: A QUALITATIVE THEMATIC SYNTHESIS
}

\author{
David Pannocchia, Petra Saskia Bayerl and Karen Latricia Hough \\ CENTRIC, Sheffield Hallam University, 20 Furnival St., Sheffield, UK, S1 2NU
}

\begin{abstract}
The highly complex economic, political, social and cultural processes of migration are increasingly digitally mediated. A rich area of research examining this phenomenon is emerging at the confluence of information and communication technology (ICT) and social sciences. However, little has been done to systematically review this literature. Through a qualitative thematic synthesis (QTS), this paper presents a fusion of recent research to identify: 1) what technologies are being used by migrants to the EU and how and 2) what are the impacts of technology on migrants and migration processes. By bridging the findings of multidisciplinary works, this QTS demonstrates how digital media and technology affect migrant experiences in both positive and negative ways as well as evidence of their impact on migratory trends. It highlights key gaps in the literature and suggests further areas for intervention, identifying the need for a cross-disciplinary research agenda that addresses causal relationships between effects of technology and migration processes.
\end{abstract}

\section{KEYWORDS}

Migration, Social Media, ICT, Literature Review, Qualitative Synthesis

\section{INTRODUCTION}

Just as digital media and technologies permeate the fabric of daily life, so too have they become an integral part of the migrants' journeys. This reality has received considerable attention in academia and public discourse, particularly within the context of the influx of migratory movements into the EU since 2014. In this debate, migrant uses of technology are often portraited from opposite or at least ambiguous positions - as solutions on the one side (Panagakos \& Horst, 2006) or as channel for a 'politics of dehumanisation' on the other (Awad \& Tossell, 2019). Studies investigating the phenomenon of 'connected migrants' (Leurs \& Pozanesi, 2018) and 'e-diasporas' (Diminescu, 2012) are broad and varied, traversing disciplines from information and communication technology (ICT) studies to sociology and from large-n quantitative studies to in-depth ethnographic work.

The aim of this paper is to synthesise recent research on how digital media and technologies are used by migrants and their impact on migration processes in order to foreground gaps in our understanding of the role of digital mediation in migrant experiences and decision-making. The findings are a subset of data collected for a systematic literature review (SLR) examining narratives of migration to Europe as part of the EU H2020 project PERCEPTIONS. Through a qualitative thematic synthesis (QTS), this paper presents an amalgamation of recent research and highlights the need for a cross-disciplinary research agenda to examine this highly salient phenomenon.

\section{METHODOLOGY}

Our study is based on a qualitative thematic synthesis (QTS). QTS aims to achieve transparency and rigor in literature reviews by adopting systematic procedures in collecting, selecting and analysing literature while utilising qualitative methods to cross-examine shared or diverging themes (Bearman \& Dawson, 2013). This entails that QTS is well situated to examine heterogeneous samples that use diverse methods and hypotheses (Barnett-Page \& Thomas, 2009). As such, it is an appropriate method to systematically survey research in 
multi-disciplinary areas such as migration studies that traverse fields from sociology, political sciences and criminology to psychology and health, amongst others.

The sample for this QTS was drawn from a larger dataset developed as part of PERCEPTIONS. Systematic collection and selection procedures were implemented in five phases. Identification of sources found 856 articles through systematic searches using Boolean search strings containing combinations of keywords such as 'Migration', 'ICT' and 'Social Media'. 225 sources were excluded at this stage due to geographical location, date of publication, language and missing data. During the screening phase, titles and abstracts of the remaining 631 documents were assessed for eligibility leading to 374 exclusions due to duplications, topical irrelevance and lack of access. Further eligibility was determined through a full text review of the remaining 257 sources leading to 36 further exclusions based on their topical relevance and quality. Within this dataset of 221 sources published since 2014 and focused on current migration movements to the EU, 41 sources were identified as relevant for this QTS and were thematically coded using NVivo. The sample was analysed in order to answer the following research questions: What digital media and technologies are used by migrants to the EU and for what purposes? And what are the impacts of these technologies on migrants and migration processes?

\section{KEY FINDINGS}

There was significant evidence across the sampled literature that digital technologies have become a vital and intrinsic element to migration journeys from departure and transit to settlement in destination countries. Within the dataset, sources explicitly referenced smart and mobile phones $(n=28)$, computers and tablets $(n=6)$, GPS $(\mathrm{n}=5)$, digital infrastructures $(\mathrm{n}=4)$ as well as e-currency and blockchains $(\mathrm{n}=1)$ as being key digital technologies used by migrants. The primary digital media platforms discussed were Facebook and Messenger $(n=31)$, Twitter $(n=14)$, WhatsApp $(n=13)$, Skype $(n=10)$, Instagram $(n=4)$, Google apps like YouTube $(n=3)$, $\operatorname{Viber}(n=3)$ and dating apps such as Tinder and $\operatorname{Grindr}(n=2)$. The following sections explore the major themes that emerged from the sample of how these technologies are used and their effects on migrants and migratory trends.

\subsection{Migrant uses of Digital Media and Technologies}

Reported migrant uses of digital media and technology reflect those of the broader population, yet often within the context of migration aspirations and necessities. A key overarching theme was that ICT enables migrants to the EU to gain information about their destinations and provided channels of communication between countries of origin and destination (Bakewell \& Jolivet, 2015; Dekker et al., 2016; Dhoest, 2019; Milivojevic, 2018; Fiedler, 2019). Critically, digital media diversifies the means available for migrants to plan their journeys and find modes of entry into the EU (Coskun, 2018; Dekker et al., 2016; Fiedler, 2018; Kutscher \& Kreß, 2018; Latenero \& Kift, 2018; Mandić, 2017; Milivojevic, 2018). Within the literature, there is considerable agreement that digital media and technology are vital tools to access information and communicate with social networks throughout the journey and are adopted and adapted by individual migrants to their specific needs.

Preferences for certain technologies and specifications were also discussed. For example, computers were most commonly discussed in periods of immobility, e.g. at refugee camps (Twigt, 2018) or while integrating in destination countries (Dekker \& Engbersen, 2014). Meanwhile, smartphones were frequently referred to as essential tools at all stages of the journey, but particularly during periods of mobility (Bokert et al., 2018; Chouliaraki, 2017; Dhoest, 2019; Fiedler, 2019; Gillespie et al., 2018; Hunter, 2015; Mandić, 2017; Milivojevic, 2018; Nagy; 2018). Moreover, the literature mentions that a growing proportion of remittances are sent by migrants in Europe to countries of origin via digital transactions (Belloni, 2019 p. 3; Rodima \& Grimes, 2019; Hunter, 2015; Fiedler, 2019; Tanzanu, 2018). With access to these technologies, many migrants operate within digitally mediated contexts as archetypal agents of Harvey's (1989) 'time-space compression' with transnational connectivity to social networks and information across the globe.

Although digital technologies are widely used by migrant communities and play a growing role in mediating their experiences, there was also considerable consensus that there are 'digital divides' amongst migrant groups in terms of access to these technologies and ability to use them. These divides are largely due to disparities in digital literacy, gender and age demographics, financial capacity and, critically, ability to access infrastructures such as Wi-Fi at various stages of the journey (Arvanitis \& Yelland, 2019; Belloni, 2019; 
Dekker \& Engbersen, 2014; Dhoest, 2019 p. 3; Gillespie et al., 2018; Leurs, 2016; Kutscher \& Kreß, 2018; Maitland, 2018; Ross, 2018; Ruokolainen \& Widén, 2019; Whitteborn, 2015). Additionally, while many migrants are highly active online (Chouliaraki, 2017), some irregular migrants are aware that they may be the subject of surveillance by border authorities and prefer applications and platforms with anonymised and encryption features (Dhoest, 2019; Gillespie, et al., 2018; Kutscher \& Kreß, 2018; Whitteborn, 2015). Consequently, caution is required not to overstate the dependency of contemporary migrants on technology or generalise preferences for digital media platform, which may be highly variable between cases and at different phases of the journey.

\subsection{Impact of Technology on Migrants and Migration Processes}

While the types and uses of technology are not a significant point of contention within the sample, their impact on migrants and migration processes are. Several authors argue that digital media and technologies can enable migrants to navigate their journeys to Europe with greater ease and security (Andersson, 2019; Dhoest, 2019; Gillespie et al, 2018; Kutscher \& Kreß, 2018; Mandic, 2017; Milivojevic, 2018). The greater connectivity afforded through these mediums facilitates the formation of transnational communities between families, friends and shared sociocultural identities (Alinejad et al., 2019; Almenara-Niebla \& Ascanio-Sánchez, 2019; Bayramoğlu \& Lünenborg, 2018; Belloni, 2019; Dekker et al., 2016; Dekker \& Engbersen, 2014; Dhoest, 2019; Ferra \& Nguyen, 2017; Fiedler, 2019; Leurs, 2016; Patterson \& Leurs, 2019; Pérez \& Salgado, 2018; Tanzanu, 2018; Urchs et al., 2019). As a result, close and long ties can be developed and maintained across territorial boundaries, building transnational networks that are both a product and motor of migration.

Through these networks, crowdsourcing of information on digital platforms may serve as an impetus for departure as well as inform choices on journeys, destinations and shape expectations of the costs and benefits of migrating (Baran, 2018; Bayramoğlu \& Lünenborg, 2018; Bokert et al., 2018; Fiedler, 2019). This is argued to increase the dynamism of migration processes. Indeed, multimedia content shared by the diaspora has been argued to increase or decrease motivations for other potential migrants to the EU (Belloni, 2016; Pogliano, 2017; Fiedler, 2019; Mapelli, 2019; Nelimarkka et al., 2018; Twigt, 2018). Additionally, information gained through interpersonal communication and with greater accessibility to information online before, during and after journeys to Europe may lead to changes in travel trajectories and choices of destination (Bakewell \& Jolivet, 2015; Belloni, 2016; Borkert et al., 2018; Crawley \& Hagen, 2018; Dekker et al., 2016; Dekker $\&$ Engbersen, 2014; Fiedler, 2019). Other authors also contend that digital platforms may facilitate integration into host states by providing opportunities for social contact with hosts and increasing access to employment and services (Bayramoğlu \& Lünenborg, 2018; Dhoest, 2019).

Next to positive aspects, there are ways in which technologies may negatively impact migrants. With greater access to information and communication there are higher possibilities of encountering untrustworthy information or connecting to criminal entities such as human smugglers and traffickers via digital channels (Bokert et al., 2018; Dekker \& Engbersen, 2014). The impact of social media on migrants may also include increased anxiety and social pressures along social, cultural, economic and political dimensions (Hunter, 2015; Almenara-Niebla \& Ascanio-Sánchez, 2019; Belloni, 2019; Dhoest, 2019; Hunter, 2015; Leurs, 2016; Talhouk et al., 2019; Tanzanu, 2018). This may in fact lead to counterintuitive outcomes. For example, some authors have observed that sociocultural pressures resulting from greater transnational connectivity leads to some migrants distancing from social ties with friends and families in countries of origin (Hunter, 2015; Witteborn, 2015). Therefore, technology plays an ambivalent role that may help or hinder migrant users travelling to and integrating in Europe. What is currently lacking is an integrated view that helps to explain the mechanisms and conditions of digitalization's ambiguous role in migrants' experiences and decisions - also in their combination with non-mediated settings.

The literature also indicates reasons to be reserved about the extent to which technology impacts migration trends. While this sample points towards the digitalisation of migrant journeys, there is a considerable degree of caution in attributing a causal role to technology effects on migration trajectory. For example, Fiedler (2019) finds that close, interpersonal social networks have a stronger effect on migrant aspirations and decisions than long ties, whether online or offline. This indicates that interpersonal connections rather than the effects of digital technologies or media themselves impact migration decisions. As Dekker et al. (2016) and Maitland (2018) suggest, technology may act to mediate migration processes rather than catalyse them. The status of ICTs thus requires further investigation. 


\section{CONCLUSION}

The highly complex economic, political, social and cultural processes of migration are increasingly digitally mediated. This QTS has demonstrated key areas where research is being undertaken to examine this phenomenon. Significant strides are being made to understand which technologies and channels are used and how. Preferences for certain technologies and platforms often mirror uses of non-migrant users yet may be adapted to the context-specific requirements of migrants. Also, as is the case with virtually all uses of technology, our review outlines the potential for positive and negative impacts on migrant users as a result.

A further result of our synthesis are topics and areas that have not yet been addressed or received only passing attention. Most prominent is the lack of an integral view of digitalisation along the migration trajectory. We therefore advocate more longitudinal investigations into the shifting choices, meanings and consequences of ICTs throughout migrant journeys. Such work should also consider the parallel importance of digital and non-digital means. There is further a significant gap in research exploring causal relationships between migration and technology with regards to fundamental dynamics such as push and pull factors as well as networked nonlinear feedback mechanisms. While past studies relied largely on qualitative enquiries, issues of causality, especially in terms of long-term impacts and migration trends, require attention. Addressing this gap would help to better understand the mechanisms and conditions underlying migration trends and trajectories. In addition, digitalisation is often conceptualised as either individual or collective phenomenon, calling for greater attention to the intersections between personal and collective choices and experiences. At the same time, migrants are a highly heterogeneous group in terms of demographics, aspiration and experiences. Our review highlights a lack of systematic - and particularly comparative - investigations into specific migrant groups. For instance, we found relatively few studies investigating media choices by vulnerable groups such as unaccompanied minors, pregnant women or members of the LGBTQ+ community.

Methodologically, using QTS to explore digitalisation in the migration literature proved an effective means of surveying a highly heterogenous research landscape while maintaining a systematic approach to the collection, selection and analysis of sources. A potential limitation of our approach may be the lack of quantifiable or longitudinal analyses of this body of research to identify larger-scale trends. However, this approach may be challenged by the largely qualitative nature of studies in this area. Also, our search focused specifically on migration to the EU, limiting the scope of our review.

Ultimately, this QTS aimed to provide a survey of contemporary research and an agenda for further investigations into this rich area of research situated at the confluence of ICT and social science disciplines. Migration is a topic of tremendous societal, political and humanitarian importance. Better understanding migrants' experiences and choices is thus not only a rewarding research exercise but can support ICT developments and policies that address migration realistically and in its full complexity.

\section{ACKNOWLEDGEMENT}

This project has received funding from the European Union's Horizon 2020 Research and Innovation Programme under Grant Agreement No 833870. We would like to thank the PERCEPTIONS Consortium for their contributions to the dataset that forms the basis of this paper.

\section{REFERENCES}

Alinejad, D., Candidatu, L., Mevsimler, M., Minchilli, C., Ponzanesi, S. and Van Der Vlist, F.N. (2019), Diaspora and mapping methodologies: tracing transnational digital connections with 'mattering maps'. Global Networks, 19: 21-43.

Almenara-Niebla, S., \& Ascanio-Sánchez, C. (2019). Connected Sahrawi refugee diaspora in Spain: Gender, social media and digital transnational gossip. European Journal of Cultural Studies. 1-16.

Andersson, K.B. (2019). Digital Diasporas: An Overview of the Research Areas of Migration and New Media through a Narrative Literature Review. Human Technology, 15(2), 142-180.

Arvanitis, E. \& Yelland, N. (2019). Home Means Everything to Me ...': A Study of Young Syrian Refugees' Narratives Constructing Home in Greece. Journal of Refugee Studies. 
Awad, I. \& Tossell, J. (2019). Is the smartphone always a smart choice? Against the utilitarian view of the 'connected migrant'. Information, Communication \& Society.

Bakewell, O., \& Jolivet, J. (2015). Broadcast feedback as causal mechanisms for migration. (International Migration Institute working papers, Oxford university, paper 113), retrieved from Migration Institute website: https://www.migrationinstitute.org/publications/wp-113-15.

Baran, D.M. (2018). Narratives of migration on Facebook: Belonging and identity among former fellow refugees. Language in Society, 47, 245-268.

Barnett-Page, E., Thomas, J. (2009). Methods for the synthesis of qualitative research: a critical review. BMC Med Res Methodol 9, 59.

Bayramoğlu, Y., \& Lünenborg, M. (2018). Queer Migration and Digital Affects: Refugees Navigating from the Middle East via Turkey to Germany. Sexuality \& Culture, 22 1019-1036.

Bearman, M. \& Dawson, P. (2013). Qualitative synthesis and systematic review in health professions education. Medical Education. 47, 252-260.

Belloni, M. (2016). Refugees as Gamblers: Eritreans Seeking to Migrate Through Italy. Journal of Immigrant \& Refugee Studies, 14(1), 104-119.

Belloni, M. (2019). When the phone stops ringing: on the meanings and causes of disruptions in communication between Eritrean refugees and their families back home. Global Networks, a journal of transnational affairs. 1-18.

Borkert, M., Fisher, K.E. \& Yafi, E. (2018). The Best, the Worst, and the Hardest to Find: How People, Mobiles, and Social Media Connect Migrants In(to) Europe. Social Media + Society.

Chouliaraki, L. (2017). Symbolic bordering: The self-representation of migrants and refugees in digital news. Popular Communication, 15 (2), 78-94.

Coskun, E. (2018). Criminalisation and prostitution of migrant women in Turkey: A case study of Ugandan women. Women's Studies International Forum, 68, 85-93.

Crawley, H., \& Hagen-Zanker, J. (2018). Deciding Where to go: Policies, People and Perceptions Shaping Destination Preferences. International Migration Vol. 57 (1) 20-35.

Dekker, R. \& Engbersen, G. (2014). How social media transform migrant networks and facilitate migration, Global Networks, a journal of transnational affairs, Vol 14 (4) 401-408.

Dekker, R., Engbersen, G., \& Faber, M. (2016). The use of online media in migration networks. Population, Place and Space, 22, 539-551.

Dhoest, A. (2019). Digital (dis)connectivity in fraught contexts: The case of gay refugees in Belgium. European Journal of Cultural Studies $1-17$.

Diminescu, D. (2012). Introduction: Digital methods for the exploration, analysis and mapping of e-diasporas. Social Science Information, 51(4), 451-458

Ferra, I., \& Nguyen, D. (2017). "\#Migrantcrisis: "tagging" the European migration crisis on Twitter". Journal of Communication Management. 21 (4) 411-426.

Fiedler, A. (2019). The gap between here and there: Communication and information processes in the migration context of Syrian and Iraqi refugees on their way to Germany. The International Communication Gazette, 81(4), 327-345.

Gillespie, M., Osseiran, S., \& Cheesman, M. (2018). Syrian Refugees and the Digital Passage to Europe: Smartphone Infrastructures and Affordances. Social Media + Society.

Hardy, D. (1989). The condition of Modernity: An Enquiry into the Origins of Cultural Change. Oxford: Blackwell

Hunter, A. (2015). Empowering or impeding return migration? ICT, mobile phones, and older migrants' communications with home. Global networks, a journal of transnational affairs, Vol 15 (4) 485-502.

Jones, K. (2004). Mission Drift in Qualitative Research, or Moving Toward a Systematic Review of Qualitative Studies, Moving Back to a More Systematic Narrative Review. The Qualitative Report, 9(1): 95-112.

Kutscher, N. \& Kreß, L.-M. (2018). The Ambivalent Potentials of Social Media Use by Unaccompanied Minor Refugees. Social Media + Society.

Latenero, M., \& Kift, P (2018). On Digital Passages and Borders: Refugees and the New Infrastructure for Movement and Control. Social Media + Society, $1-11$

Leurs, K. \& Ponzanesi, S. (2018) Connected migrants: Encapsulation and cosmopolitanization. Popular Communication, $16: 1,4-20$.

Leurs, K. (2016) Young connected migrants and non-normative European family life: exploring affective human right claims of young e-diasporas. International Journal of EPolitics, 7(3), 15-34.

Maitland, C (ed.) (2018). Digital Lifeline? ICTs for Refugees and Displaced Persons. Cambridge: MIT Press.

Mandić, D. (2017). Trafficking and Syrian Refugee Smuggling: Evidence from the Balkan Route. Social Inclusion, 5(2), 28-38. 
Mappelli, G. (2019). The Identity Construction of Migrants on Facebook. Languages, 4, (52).

Mendoza Pérez, K., Morgade Salgado, M. (2019). Unaccompanied' Minors? Accompanied Foreign Minors, Families and New Technologies. Int. Migration \& Integration 20, 121-136.

Milivojevic, S. (2019). 'Stealing the fire', 2.0 style? Technology, the pursuit of mobility, social memory and de-securitization of migration. Theoretical Criminology, 23(2), 211-227.

Nagy, V. (2018). Roma Networks: Ethnic Solidarity in an Internet Age? Intersections. EEJSP, 4(3), 158-179.

Nelimarkka, M. Laaksonen, S-M. \& Semaan, B. (2018). Social Media Is Polarized, Social Media Is Polarized: Towards a New Design Agenda for Mitigating Polarization. In Proceedings of the 2018 Designing Interactive Systems Conference (DIS '18). Association for Computing Machinery, New York, NY, USA, 957-970

Panagakos, A.N. and Horst, H.A. (2006). Return to Cyberia: technology and the social worlds of transnational migrants. Global Networks, 6: 109-124.

Patterson, J. and Leurs, K. (2019). 'We Live Here, and We Are Queer!' Young Adult Gay Connected Migrants' Transnational Ties and Integration in the Netherlands. Media and Communication, 7(1), 90-101.

Pogliano, A. (2017). Media, Migration, and Sociology. A Critical Review. Sociologica, 1.

Rodima-Taylor, D. \& Grimes, W.W. (2019). Virtualizing diaspora: new digital technologies in the emerging transnational space. Global Networks, 19(3), 349-370.

Ross, A. (2018). Young Europeans: A New Political Generation? Societies, 8, 70

Ruokolainen, G., \& Widén, H. (2019). Conceptualising misinformation in the context of asylum seekers. Information Processing and Management, 102127, 1-6.

Talhouk, R., M. Balaam, A. L. Toombs, A. Garbett, C. Akik, H. Ghattas, V. Araujo-Soares, B. Ahmad, \& K. Montague (2019). Involving Syrian Refugees in Design Research: Lessons Learnt from the Field. In Proceedings of the 2019 on Designing Interactive Systems Conference, 1583-1594. New York, NY: ACM.

Tazanu. P.M. (2018). Communication technologies and legitimate consumption: making sense of healthcare remittances in Cameroonian transnational relationships. Africa, 88(2), 385-403.

Twigt, M. A. (2018). The Mediation of Hope: Digital Technologies and Affective Affordances Within Iraqi Refugee Households in Jordan. Social Media + Society.

Urchs, S., Wendlinger, L.. Mitrović, J. \& Granitzer, M. (2019). MMoveT15: A Twitter Dataset for Extracting and Analysing Migration-Movement Data of the European Migration Crisis 2015. In IEEE 28th International Conference on Enabling Technologies: Infrastructure for Collaborative Enterprises (WETICE). Napoli, Italy, 146-149.

Witteborn, S. (2015). Becoming (Im)Perceptible: Forced Migrants and Virtual Practice. Journal of Refugee Studies, 28(3), 350-367. 